\title{
Torasemide significantly reduces thiazide-induced potassium and magnesium loss despite supra-additive natriuresis
}

\author{
H. Knauf • E. Mutschler • H. Velazquez • G. Giebisch
}

Received: 12 November 2008 / Accepted: 23 January 2009 /Published online: 20 February 2009

(C) The Author(s) 2009. This article is published with open access at Springerlink.com

\begin{abstract}
Background Resistance to high-dose loop diuretics can be overcome either by co-administration with thiazides or by treatment with medium-dose loop diuretics combined with thiazides. Combination therapy has been proven to be superior to high-dose loop diuretic monotherapy for cardiac and renal edema. However, such a strongly efficacious short-term regimen is often complicated by undesired effects, including circulatory collapse and electrolyte disturbances. The question of whether the loop diuretic/ thiazide combinations are efficacious and safe when conventional doses are combined has not yet been answered.

Methods The effects of hydrochlorothiazide (HCT) and torasemide (TO) given alone on the excretion of $\mathrm{Na}^{+}, \mathrm{Cl}^{-}$, $\mathrm{K}^{+}, \mathrm{Mg}^{2+}$, and $\mathrm{Ca}^{2+}$ were compared with the effects of combined administration of the diuretics in 12 healthy volunteers.

Results The co-administration of HCT (25 mg) with TO (5 or $10 \mathrm{mg}$ ) strongly increased $\mathrm{Na}^{+}$excretion. However, the

H. Knauf $(\bowtie)$

Department of Medicine 1, St. Bernward-Krankenhaus,

31134 Hildesheim, Germany

e-mail: heinrich.knauf@t-online.de

E. Mutschler

Pharmacological Institute, University of Frankfurt/Main,

Frankfurt am Main, Germany

H. Velazquez

Research Office, VA Healthcare System,

West Haven, CT 06516, USA

G. Giebisch

Department of Cellular \& Molecular Physiology,

Yale University, School of Medicine,

New Haven, CT 06520, USA
\end{abstract}

combination significantly reduced $\mathrm{K}^{+}$and $\mathrm{Mg}^{2+}$ excretion. The $\mathrm{K}^{+}$-sparing effect of the HCT/TO combination was shown to be due to a significant reduction in the HCTinduced increase in fractional $\mathrm{K}^{+}$excretion by the loop diuretic. Total excretion of $\mathrm{Ca}^{2+}$ relative to $\mathrm{Na}^{+}$excretion was less with the HCT/TO combination than with TO given alone.

Conclusion The enhancement of desired $\mathrm{NaCl}$ excretion by the HCT/TO combination with significant reduction of undesired loss of $\mathrm{K}^{+}$and $\mathrm{Mg}^{2+}$ meets clinical requirements but has to be validated in long-term clinical trials.

Keywords Hydrochlorothiazide - Torasemide ·

Combination therapy · Supra-additive natriuresis ·

Potassium and magnesium sparing effects

\section{Introduction}

High-dose monotherapy with loop diuretics has successfully been replaced by the administration of medium-dose loop diuretics combined with thiazides in patients with chronic edema and chronic renal failure [1-12]. Such combinations of diuretics, each acting on different segments of the nephron-known as "sequential nephron blockade"-break the resistance to diuretics in edematous states [13-27]. Although this physiologically grounded rationale is more effective than high-dose monotherapy when a rapid and robust diuretic response is needed, such treatment may lead to complications such as fluid and electrolyte disturbances [13, 28, 29].

Conventional-dose combinations of loop diuretics (e.g., 5 or $10 \mathrm{mg}$ torasemide) and thiazides (e.g., $25 \mathrm{mg}$ hydrochlorothiazide) have so far not been introduced in 
clinical practice for the long-term treatment of hypertension or chronic heart failure. This is obviously due to the clinical experience that high-dose loop/thiazide diuretic combinations cause electrolyte disturbances.

In the present study, we examined conventional dose combinations of loop diuretics and thiazides in healthy volunteers free of any patient bias with particular focus on the relationship between sodium, potassium, and magnesium excretion.

\section{Methods}

The ethically approved trial (University of Göttingen, Germany) was performed on 12 healthy volunteers (2848 years old, 6 male, 6 female), who had given their written informed consent to the study. Prior to administration of a drug, they underwent a clinical check-up including kidney, liver, and hematological tests, and ECG. The participants were free of any medication. They were kept on a standard diet, receiving a defined fluid (1.5 1/day) and salt intake (100 mmole $\mathrm{Na}^{+}$and 80 mmole $\mathrm{K}^{+}$per day) 3 days before and throughout the study. At least 1 week wash-out period was introduced between series.

\section{Diuretics used}

As a representative thiazide, hydrochlorothiazide (HCT, HEXAL Pharmaceuticals), $25 \mathrm{mg}$, was used in the study since it has been available for long time and the greatest body of evidence and experience has been accumulated for it [30]. Torasemide (TO, HEXAL Pharmaceuticals), 5 or $10 \mathrm{mg}$, is a "newer" loop diuretic of the furosemide-type with a longer duration of action and a significantly higher bioavailability $[31,32]$. The diuretics were given alone and in combination. All diuretics were given orally in a single dose under clinical control of the monitor of the trial.

\section{Study protocol and analysis}

In accordance with earlier studies [32, 33], urine was collected after drug administration ( 8 A.M.) in the hospital for a $24-\mathrm{h}$ period, divided into two 3 -h collections, one 6-h collection, and one $12-\mathrm{h}$ collection. Baseline (control) collections were obtained from 24 to $0 \mathrm{~h}$ prior to drug administration using the same intervals (i.e., $-24,-21,-18$, $-12,0 \mathrm{~h})$. An aliquot of the defined volume of the respective collection period was frozen until analyzed for $\mathrm{Na}^{+}, \mathrm{Cl}^{-}, \mathrm{K}^{+}, \mathrm{Mg}^{2+}, \mathrm{Ca}^{2+}$, and creatinine using a MODULAR Analyzer (Roche, Switzerland). For monitor-
Fig. 1 Effect of co-administered loop diuretic torasemide (TO), 5 or $10 \mathrm{mg}$, with hydrochlorothiazide (HCT), $25 \mathrm{mg}$, on total excretion of $\mathrm{Na}^{+}$(upper panel) and on the excretion of $\mathrm{K}^{+}$and $\mathrm{Mg}^{2+}$ (lower panel) as compared to HCT alone. The left bar presents the data for $0-12 \mathrm{~h}$, the right bar for $0-24 \mathrm{~h}$ collection periods. The data are means \pm SE for 12 healthy volunteers. For controls, further excretion data, and statistical analysis, see Table 1

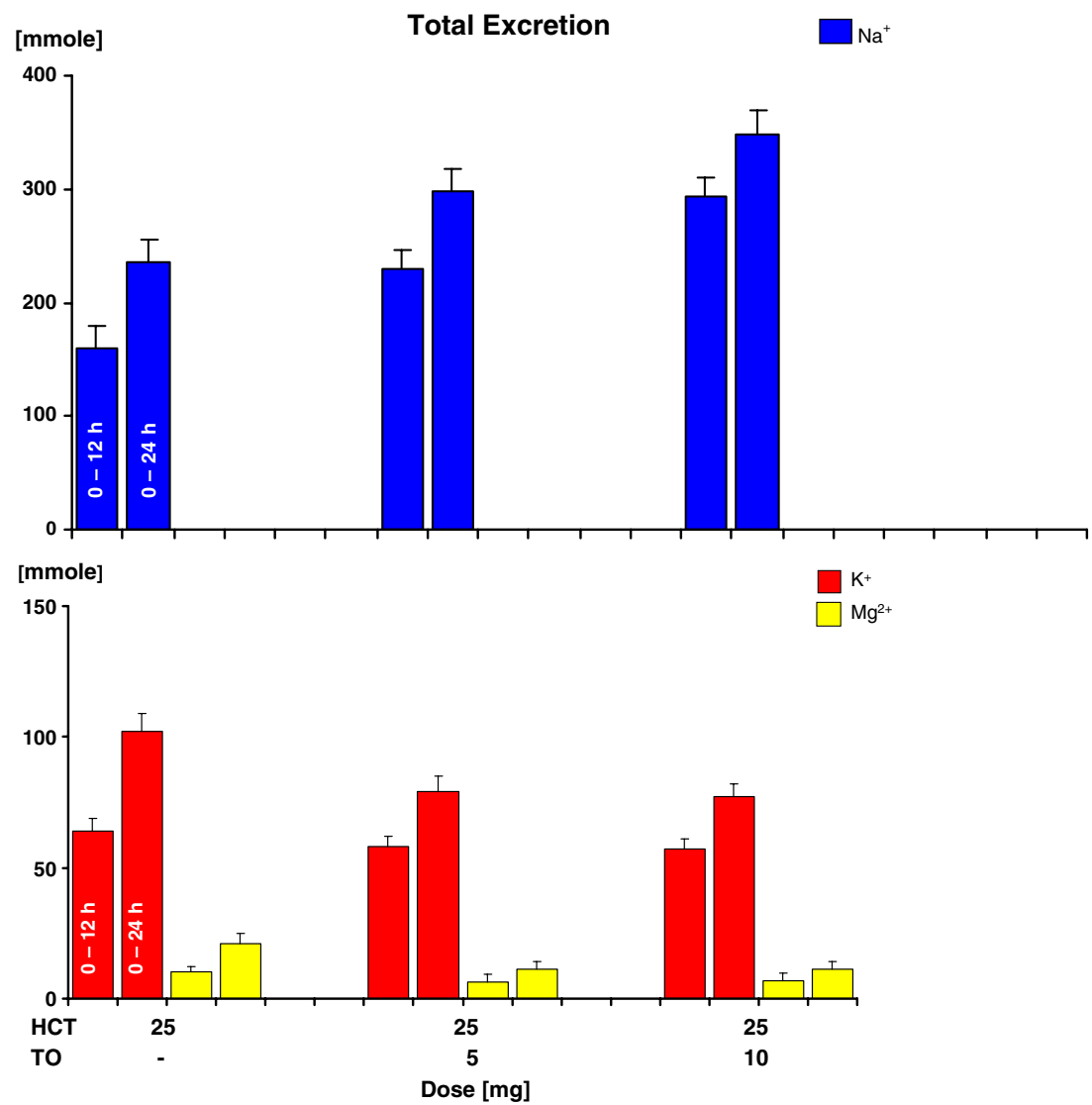


ing the glomerular filtration rate (GFR) and the fractional excretion of $\mathrm{K}^{+}, \mathrm{FE}_{\mathrm{K}}$, plasma creatinine, and plasma $\mathrm{K}^{+}$ were taken prior to the study as well as $3,6,12$, and $24 \mathrm{~h}$ after drug administration. $\mathrm{FE}_{\mathrm{K}}$ represents the amount of $\mathrm{K}^{+}$ excreted in the urine relative to the amount filtered (GFR $\times$ plasma $\mathrm{K}^{+}$).

First, total excretion of volume and electrolytes was determined from urine collected in the respective periods. Then net excretion induced by a diuretic regimen was calculated for each participant from total excretion minus baseline (control) obtained in the respective pretreatment period. Thus, each run or experimental series was compared with its own control $24 \mathrm{~h}$ prior to drug administration.

\section{Statistical analysis}

Administration of the diuretics alone and the diuretic combination was performed in a randomized design. All data are expressed as mean values \pm SE. Statistical evaluation was performed using analysis of variance adjusted for multiple testing. Statistical significance was accepted when $P<0.05$.

\section{Results}

Figure 1 illustrates total excretion rates of $\mathrm{Na}^{+}, \mathrm{K}^{+}$, and $\mathrm{Mg}^{2+}$ obtained in 0 - to $12-\mathrm{h}$ and 0 - to $24-\mathrm{h}$ collection periods. Hydrochlorothiazide (HCT, $25 \mathrm{mg}$ ) induced a strong natriuresis for $12 \mathrm{~h}$, consistent with the time of action of this diuretic. The addition of the loop diuretic TO, 5 or $10 \mathrm{mg}$, to HCT strongly increased $\mathrm{Na}^{+}$excretion in a dose-dependent manner. With respect to a once-a-day drug administration, which includes the postdiuretic period (12$24 \mathrm{~h}$ ), the co-administration of HCT with TO increased total $\mathrm{Na}^{+}$excretion without being curtailed by postdiuretic $\mathrm{Na}^{+}$ retention.

Strikingly, $\mathrm{K}^{+}$excretion did not increase in proportion to $\mathrm{Na}^{+}$excretion. Rather, $\mathrm{K}^{+}$excretion declined with increasing doses of TO co-administered with the thiazide. HCTinduced excretion of $\mathrm{Mg}^{2+}$ was also reduced by increasing doses of TO. These findings were then analyzed in detail by a statistical evaluation of the excretion data given in Table 1.

Compared to controls, HCT induced strong $\mathrm{Na}^{+}$and $\mathrm{Cl}^{-}$ excretion. Positive $\mathrm{NaCl}$ excretion was maintained up to $24 \mathrm{~h}$ after drug administration. TO, however, induced significant $\mathrm{Na}^{+}$excretion only for $0-12 \mathrm{~h}$. In terms of mmoles, the HCT-induced excretion of $\mathrm{K}^{+}$was about $40 \%$ that of $\mathrm{Na}^{+}$. TO, however, was significantly less kaliuretic than HCT. The loop diuretic did not increase $\mathrm{K}^{+}$excretion above control for the 0 - to 12 -h or 0 - to $24-\mathrm{h}$ periods. Diuretic-induced excretion of $\mathrm{Mg}^{2+}$ very much paralleled

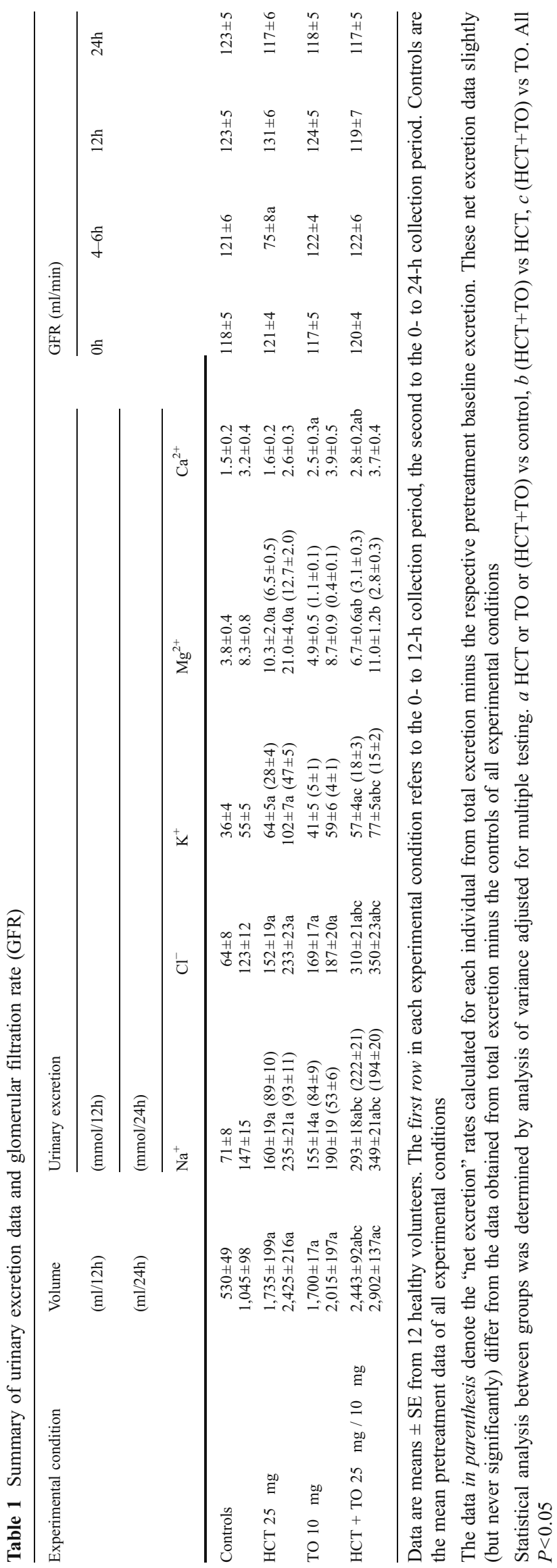


that of $\mathrm{K}^{+}$: HCT induced strong $\mathrm{Mg}^{2+}$ loss for $0-12$ and 0-24 h as well, whereas TO did not significantly change total $\mathrm{Mg}^{2+}$ excretion compared to controls. Concerning $\mathrm{Ca}^{2+}$ excretion, there was no $\mathrm{Ca}^{2+}$ loss during the 0 - to $12-\mathrm{h}$ and 0 - to 24-h periods with HCT, whereas the loop diuretic significantly increased $\mathrm{Ca}^{2+}$ excretion above control for the 0 - to $12-\mathrm{h}$ period only.

A comparison of combined administration of HCT and TO versus HCT given alone shows that the combination is a significantly stronger natriuretic regimen than HCT, both for the 0 - to $12-\mathrm{h}$ and the 0 - to $24-\mathrm{h}$ period. Total excretion of $\mathrm{K}^{+}$relative to $\mathrm{Na}^{+}$during $0-24 \mathrm{~h}$ was only $20 \%$ as compared to $40 \%$ with HCT given alone. Also $\mathrm{Mg}^{2+}$ excretion was significantly reduced by the HCT/TO combination as compared to $\mathrm{HCT}$ given alone. $\mathrm{Ca}^{2+}$ excretion obtained by the HCT/TO combination was greater than that with HCT given alone only for $0-12 \mathrm{~h}$. On the other hand, a comparison of the HCT/TO combination with TO given alone shows that total $\mathrm{Ca}^{2+}$ excretion induced by the combination did not differ significantly from that obtained with the loop diuretic given alone, although the HCT/TO combination was by far a stronger natriuretic regimen. Stated differently, total excretion of $\mathrm{Ca}^{2+}$ relative to $\mathrm{Na}^{+}$excretion with the HCT/TO combination equalled that with HCT given alone, but was less than that obtained by the loop diuretic given alone. Table 1 also includes the HCT-induced transient fall in GFR (4-6 h after medication). This phenomenon was absent in the presence of TO, in agreement with earlier reports [33].

Urinary excretion following drug administration is a complex process as the drug effect is superimposed upon or mixed with the baseline excretion of the kidney. Therefore, we focused on the drug effect per se by calculating "net excretion" rates free of the baseline excretion. Net excretion was determined for each individual by taking into account the baseline excretion in the respective pretreatment period (see Table 1). The net natriuretic effect obtained by combined administration of HCT (25 mg) and TO (10 mg) was always significantly greater than the sum of the net effects obtained by the components given alone. This "supra-additive" natriuretic effect of the thiazide/loop diuretic combination in healthy young volunteers exceeds the sum of the individual effects by a factor of 1.3. It should be noted (not given in Table 1) that the lower-dose combinations of HCT $(25 \mathrm{mg}) / \mathrm{TO}(5 \mathrm{mg})$ and HCT $(12.5 \mathrm{mg}) / \mathrm{TO}(5 \mathrm{mg})$ also resulted in a significant increase in natriuresis of $30 \%$. This phenomenon is in agreement with earlier observations in edematous patients (see the "Introduction" section).

In Fig. 2, the natriuretic net effects of HCT (25 mg) and TO $(10 \mathrm{mg})$ are plotted for the distinct collection periods. The net effects of HCT and TO given separately are combined in a single bar to be matched against the second bar presenting the net natriuretic effect induced by combined administration of HCT and TO. The time course in Fig. 2 shows that the net diuretic effect of the loop diuretic TO given alone was positive only for $6 \mathrm{~h}$ (periods 0-3 and 3-6 h). Throughout the remainder of the study period (6-12 h, 12-24 h), net sodium excretion became negative. After approximately $6 \mathrm{~h}$, significant $\mathrm{NaCl}$ retention occurred resulting in a "rebound effect" $\left(\mathrm{Na}^{+}\right.$ excretion below baseline) that diminished the overall natriuretic effect. In contrast, the thiazide diuretic acted for approximately $12 \mathrm{~h}$ and lacked a significant rebound effect. The rebound seen with TO given alone is effectively reduced by co-administered HCT. Figure 2 illustrates that combined administration of conventional doses of HCT and TO is by far a stronger natriuretic regimen ("supraadditive") than when the components are given separately.

The diuretic-induced net excretion of $\mathrm{K}^{+}$and $\mathrm{Mg}^{2+}$ is illustrated in Fig. 3. After $12 \mathrm{~h}$, combined administration of $25 \mathrm{mg}$ HCT with $10 \mathrm{mg}$ TO induced a net $\mathrm{K}^{+}$excretion of only about half the amount obtained by the individual components given separately. The attenuation of HCTinduced $\mathrm{K}^{+}$loss by TO is also clearly demonstrated for the 0 - to $24-\mathrm{h}$ period: $\mathrm{K}^{+}$loss following separate administration of HCT and TO combined in the left bar was lowered to about one-third by combined administration of HCT and TO (right bar). The same effects held true for net $\mathrm{Mg}^{2+}$ excretion both for the 0 - to $12-\mathrm{h}$ and the 0 - to $24-\mathrm{h}$ period.

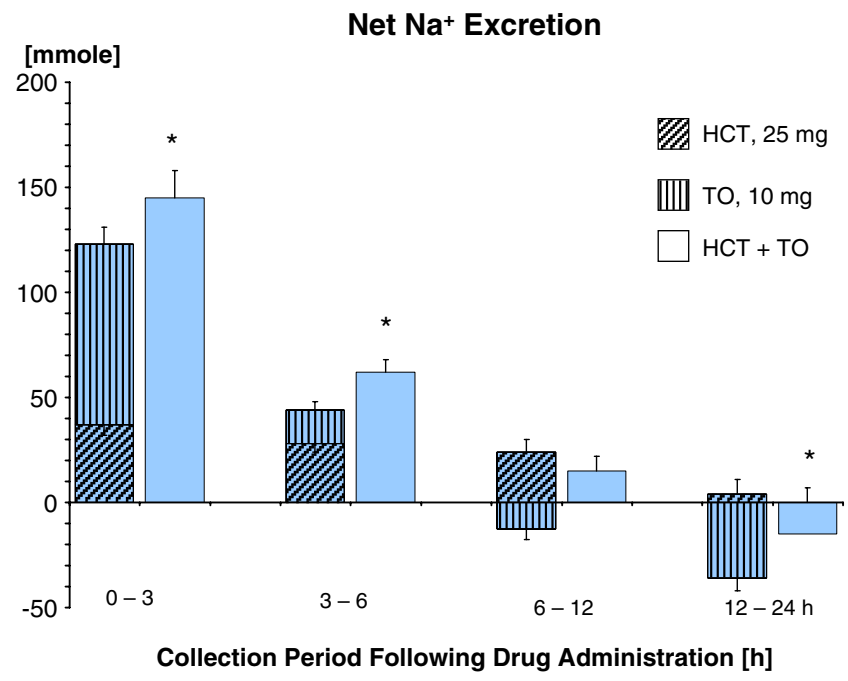

Fig. 2 Effect of HCT, $25 \mathrm{mg}$, and TO, $10 \mathrm{mg}$, and the combination of both diuretics on "net excretion" of $\mathrm{Na}^{+}$. The data are plotted for distinct collection periods to illustrate the time courses of the different regimens. Net excretion was calculated as total excretion minus the respective pretreatment baseline excretion in each individual for each regimen. The effects of the components alone are combined in the left bar to compare with the effect obtained by combined administration in the right bar. Negative excretion (e.g., with TO from 6-24 h) denotes less natriuresis than baseline excretion ("rebound"). Effect of combined administration vs the sum of the individual effects: $* P<0.05$ 

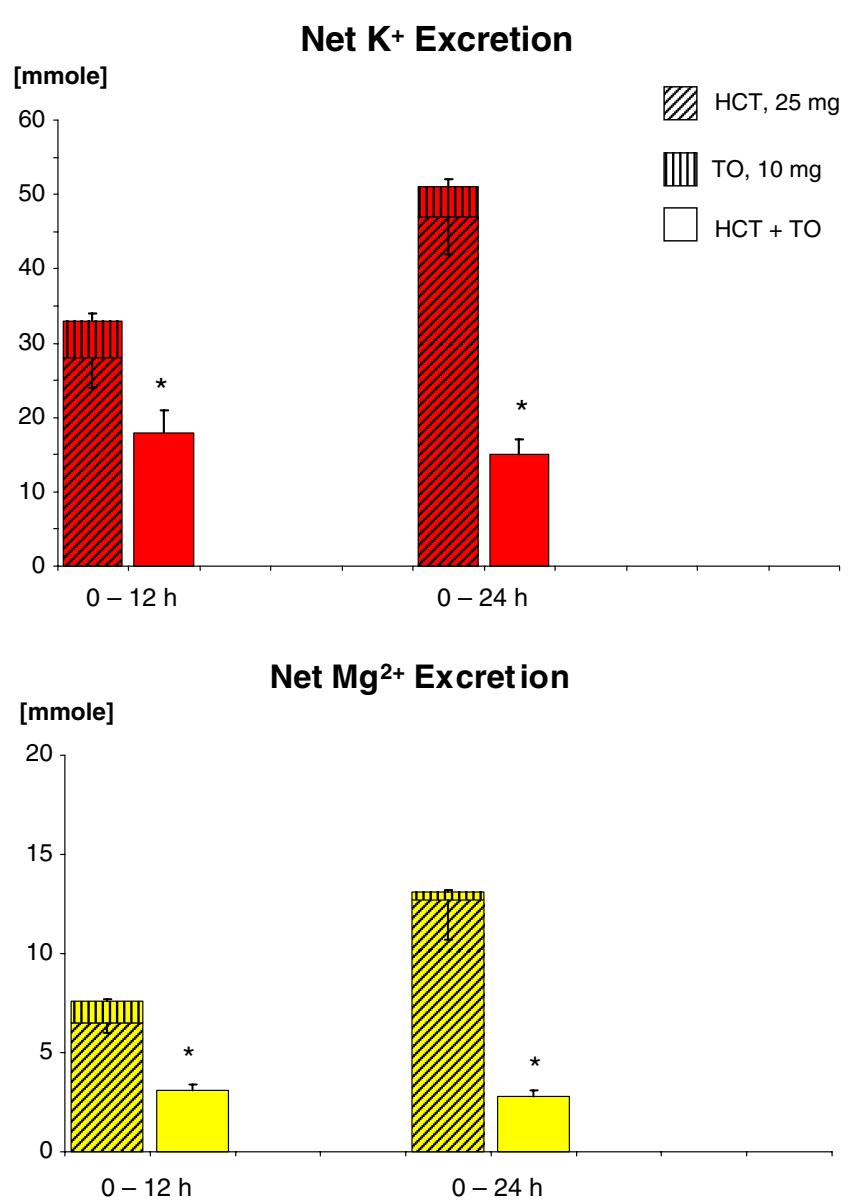

Collection Period Following Drug Administration

Fig. 3 Effect of HCT, $25 \mathrm{mg}$, and TO, $10 \mathrm{mg}$, alone, and the combination of both diuretics on net excretion of $\mathrm{K}^{+}$(upper panel) and $\mathrm{Mg}^{2+}$ (lower panel) plotted in paired bars (means $\pm \mathrm{SE}$ ). As in Fig. 2, the effects of the diuretics HCT and TO given alone are combined in the left bar to compare with combined administration in the right bar. Data are cumulative for 0 - to 12 -h and 0 - to 24$\mathrm{h}$ collection periods (see Table 1, data in parenthesis). Effect of combined administration vs the sum of the single effects: $* P<0.05$

It should be mentioned that the significant attenuation of $\mathrm{K}^{+}$ and $\mathrm{Mg}^{2+}$ excretion was also obtained by the lower dose combinations of HCT and TO.

To focus on renal handling of potassium filtration and excretion, the fractional $\mathrm{K}^{+}$excretion was studied in the presence of conventional doses of the thiazide and the loop diuretic given alone and in combination. As illustrated in Fig. 4, the $\mathrm{FE}_{\mathrm{K}}$ following the administration of $25 \mathrm{mg} \mathrm{HCT}$ significantly increased during the 0 - to 3 -h period and most evidently during the 3 - to 6 -h period to more than three times baseline $\mathrm{FE}_{\mathrm{K}}$ of 0.1 on average. However, the loop diuretic $\mathrm{TO}, 10 \mathrm{mg}$, did not significantly increase $\mathrm{FE}_{\mathrm{K}}$ during these periods. Strikingly, the loop diuretic coadministered with the thiazide significantly reduced the HCT-induced increase in $\mathrm{FE}_{\mathrm{K}}$ during the time of action of the thiazide, as also illustrated in Fig. 3. In the postdiuretic period, the $\mathrm{FE}_{\mathrm{K}}$ of the HCT-containing regimen was still slightly above baseline. Neither changes in blood chemistry nor adverse drug reactions were observed throughout the trial.

\section{Discussion}

The present experiments have shown that the coadministration of conventional and lower doses of loop and thiazide diuretics yielded a net diuretic/natriuretic effect that was significantly greater than the sum of the net individual effects of each class of diuretic. This finding is in accordance with earlier observations first made in patients with fluid retention (see the "Introduction" section). The gain in natriuretic efficacy of about $30 \%$ in healthy young volunteers needs further consideration. The addition of a loop diuretic to a thiazide may enhance $\mathrm{NaCl}$ excretion by several mechanisms, none of which are mutually exclusive. Loop diuretics do not appear to potentiate the effect of a thiazide by altering their pharmacokinetics or bioavailability [29-31]. Rather, pharmacodynamic mechanisms seem to play the predominant role in diuretic-induced electrolyte excretion.

Given the axial organization of transport mechanisms in the different segments of the nephron and the segmentspecific inhibition of salt transport by diuretics, the result of treatment is the sum of all direct and indirect effects on solute transport along the nephron. For example, when $\mathrm{NaCl}$ reabsorption along the thick ascending limb of Henle's loop (TALH) is inhibited by loop diuretics, the $\mathrm{NaCl}$ concentration in the fluid that enters the distal tubule

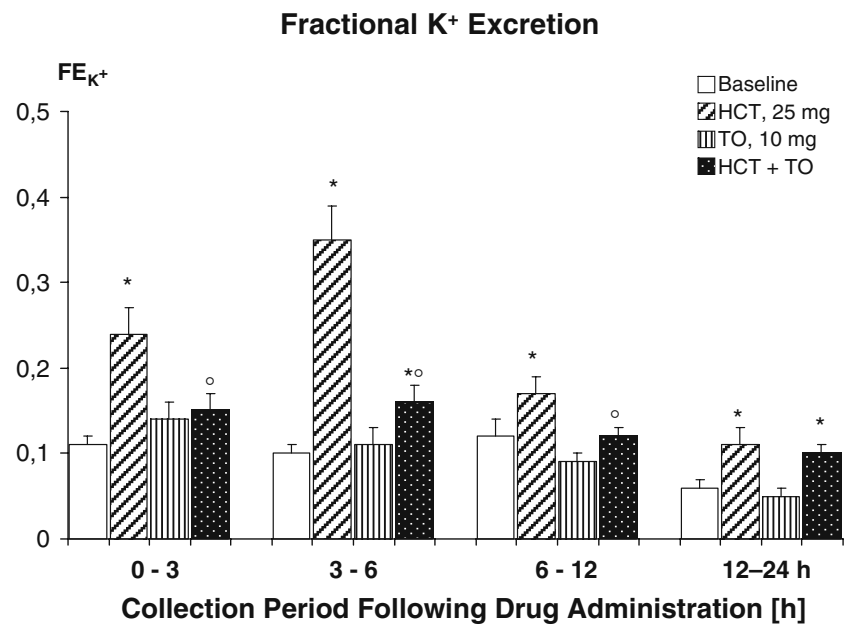

Fig. 4 Effect of HCT, $25 \mathrm{mg}$, and TO, $10 \mathrm{mg}$, alone, and the combination $\mathrm{HCT} / \mathrm{TO}$ on fractional $\mathrm{K}^{+}$excretion $\left(\mathrm{K}^{+}\right.$excreted relative to $\mathrm{K}^{+}$filtered) plotted for distinct collection periods. For comparison, control $\mathrm{FE}_{\mathrm{K}}$ is also given. The results are means $\pm \mathrm{SE}$ for 12 healthy volunteers. HCT or TO vs control: $* P<0.05$, HCT $+\mathrm{TO}$ vs HCT: ${ }^{\circ} P<0.05$ 
is greatly increased. In a microperfusion study in rats [34], $\mathrm{Na}^{+}$absorption rose by a factor of three under those conditions. As a consequence, the apparent inhibition of $\mathrm{NaCl}$ reabsorption in the loop of Henle is attenuated by increased tubular reabsorption in more distal nephron sites. This increase in sodium reabsorption can be blocked by luminal thiazide acting on the early distal tubule. Hence, the net effect of acute loop-diuretic administration on urinary $\mathrm{NaCl}$ excretion reflects the sum of effects in the diureticsensitive segment (e.g., inhibition of $\mathrm{Na}^{+} / \mathrm{K}^{+} / 2 \mathrm{Cl}^{-}$transport in the TALH) and in the loop diuretic-insensitive segments (secondary stimulation of $\mathrm{NaCl}$ reabsorption in the downstream distal tubule).

The combination of thiazides with loop diuretics prevents not only the stimulating effect of luminal $\mathrm{Na}^{+}$concentration on $\mathrm{NaCl}$ uptake in the early distal tubule, but the thiazides also inhibit carbonic anhydratase (CA) in the proximal tubule, thereby increasing $\mathrm{Na}^{+}$delivery to the TALH $[24$, 35-37]. This is due to the fact that thiazides retain a sulfamyl side group on the benzene ring characteristic of a CA inhibitor such as acetazolamide [36]. Thus, thiazides play a dual role: they block the $\mathrm{Na}^{+} / \mathrm{Cl}^{-}$co-transport in the early distal tubule and also - to varying extents - the proximal tubular CA. The order of potency for carbonic anhydratase inhibition is chlorthalidone $>$ benzthiazide $>$ polythiazide $>$ chlorothiazide $>$ bemetizide $>$ hydrochlorothiazide $>$ xipamide [36].

In addition, loop diuretics also have a dual effect: first, they block $\mathrm{Na}^{+} / \mathrm{K}^{+} / \mathrm{Cl}^{-}$transport in the TALH, and in addition, they increase $\mathrm{Ca}^{2+}$ delivery to the distal tubule [36], which decreases apical $\mathrm{Na}^{+}$conductivity of the principal cells [38]. Thus, some further $\mathrm{Na}^{+}$inhibitory effect-as is known to occur with sodium channel blockers - contributes to the supra-additive effect obtained with the combination HCT/TO.

Taken together, the HCT/TO combination inhibits $\mathrm{NaCl}$ reabsorption at four sites of the nephron: in the proximal tubule (HCT), in the loop of Henle (TO), in the early distal tubule (HCT), and in the late distal tubule (TO). This mode of action along the nephron corresponds to "sequential nephron blockade."

Thiazide monotherapy may-at least in short-term treatment - be curtailed by a transient fall in GFR and a consequent reduction in $\mathrm{Na}^{+}$excretion [33]. Through the co-administration of TO, known to block tubuloglomerular feedback [32, 33], these effects could be prevented. Postdiuretic $\mathrm{NaCl}$ retention ("rebound") is known to be more prominent the greater the peak natriuresis and the shorter the duration of the diuretic's action and is observed with loop diuretics [39]. The net effect of a strong but shortacting loop diuretic may therefore approach zero for a 24-h period. However, when combined with thiazides, the natriuretic efficacy of loop diuretics can be improved and maintained.
In long-term treatment with loop diuretics, "diuretic adaptation" [40] develops associated with epithelial hypertrophy and hyperplasia, including the activation of $\mathrm{Na}^{+} / \mathrm{K}^{+}$ATPase [34, 41]. The administration of thiazides prevented the activation of distal tubular $\mathrm{Na}^{+} / \mathrm{K}^{+}$-ATPase [42]. It was also shown in humans [43] that chronic treatment with loop diuretics enhanced ion transport in the distal tubule. These data once again support the rationale for the combined administration of loop diuretics with thiazides to counterbalance the process of diuretic adaptation.

The finding of lowered excretion of $\mathrm{K}^{+}$and $\mathrm{Mg}^{2+}$ despite the strong natriuretic efficacy of the HCT/TO combination is novel and was unexpected. However, in a previous microperfusion study in rats [35], it was shown that thiazides such as HCT or tizolemide increase distal tubular potassium secretion yielding a higher $\mathrm{K}^{+}$excretion than in controls. Yet these kaliuretic agents failed to enhance distal potassium secretion when given together with furosemide or piretanide. The inhibition of the thiazide-induced increase in distal tubular $\mathrm{K}^{+}$secretion was left unexplained at that time.

Insights gained from more recent experiments now permit a tentative explanation of the potassium-sparing effect of low-dose diuretic combinations used in this trial. Potassium is filtered by the glomeruli, and most of the potassium filtered is reabsorbed from the lumen by the time fluid emerges from the thick ascending limb of Henle's loop and enters the distal tubule. Potassium excreted in the final urine (equal to approximately $10 \%$ of the amount filtered) largely represents the amount secreted by the cells of the connecting tubule and collecting duct. Potassium secretion occurs through potassium channels, but this process also depends on the presence of luminal membrane sodium channels in the apical membrane of principal cells. The co-existence of these two channels generates the electrical driving force for potassium secretion [44]. Blocking sodium channels with $\mathrm{K}^{+}$-sparing diuretics such as amiloride, for example, decreases the driving force for potassium secretion in the distal tubule. Other agents also have been shown to block the sodium channels of the distal tubule [38]. For example, increases in luminal $\mathrm{Ca}^{2+}$ concentration in the range normally present in the distal tubule reduce net $\mathrm{K}^{+}$secretion by decreasing the electrochemical driving force for $\mathrm{K}^{+}$secretion. These data may be relevant to the present study and may help to explain the potassium-sparing effects of combined HCT/TO administration.

In rat microperfusion experiments [45], it was shown that the ability of $\mathrm{Na}^{+}$channel blockers such as amiloride to inhibit distal tubular $\mathrm{K}^{+}$secretion and $\mathrm{Na}^{+}$reabsorption requires the presence of luminal $\mathrm{Ca}^{2+}$. Since thiazides stimulate $\mathrm{Ca}^{2+}$ reabsorption by the distal tubule [36] and thus reduce the luminal $\mathrm{Ca}^{2+}$ concentration, thiazides alone 
might be expected to increase potassium excretion. Loop diuretics, on the other hand, when co-administered with thiazides might reduce $\mathrm{K}^{+}$excretion by increasing distal tubular $\mathrm{Ca}^{2+}$ concentration, inhibiting the sodium channel, and decreasing the driving force for $\mathrm{K}^{+}$secretion. Thus, the loop diuretic/thiazide combination may show a stronger antikaliuretic effect relative to $\mathrm{Na}^{+}$excretion than the antikaliuretic agent/thiazide combination. Therefore, TO may have a dual effect in the nephron: it directly blocks the $\mathrm{Na}^{+}: \mathrm{K}^{+}: \mathrm{Cl}^{-}$carrier in the TALH and, in addition, it could affect distal tubular $\mathrm{K}^{+}$secretion by increasing $\mathrm{Ca}^{2+}$ delivery as discussed above.

Given an equivalent natriuresis and diuresis, torasemide was shown to be less kaliuretic than furosemide [46, 47]. This finding was attributed to an anti-aldosteronic effect of torasemide, which was absent in furosemide [47, 48]. As shown recently, the regulation of collecting-duct $\mathrm{Na}^{+} / \mathrm{K}^{+}$-ATPase and $\mathrm{K}^{+}$excretion differs among loop diuretics. Piretanide-treated rats increase bradykinin excretion whereas furosemide-treated rats do not [49]. Bradykinin production is considered to limit apical $\mathrm{Na}^{+}$entry in principal cells. Thus, $\mathrm{Na}^{+}$reabsorption and $\mathrm{K}^{+}$secretion by the peritubular $\mathrm{Na}^{+} / \mathrm{K}^{+}$pump may not be activated. The question of whether TO also produces bradykinin and thus shows this additional mechanism to reduce $\mathrm{K}^{+}$excretion has not been investigated so far. There are, however, data such as a positive volume and $\mathrm{NaCl}$ excretion $24 \mathrm{~h}$ after dosing and a weaker kaliuretic effect of TO $[32,46,47]$ that agree with piretanide data [50] but differ from those of furosemide [46, 47, 51].

The results obtained in this study address some important clinical concerns. Thiazide-related metabolic disturbances such as hypokalemia and hypomagnesemia are dose-dependent. Since the goal of diuretic therapy is to use the lowest possible diuretic dose to achieve adequate effects, the results of this trial using conventional-dose combinations meet this requirement. In previous studies, reduction or prevention of thiazide-induced hypokalemia and hypomagnesemia was attempted with the coadministration of potassium-sparing diuretics such as amiloride [52] or triamterene [53], yielding only additive effects on net excretion of $\mathrm{Na}^{+}, \mathrm{K}^{+}$, and $\mathrm{Mg}^{2+}[54,55]$. However, the results from the present and previous studies in rats suggest that in the presence of thiazides, potassiumsparing agents such as amiloride will not be optimally effective because luminal $\mathrm{Ca}^{2+}$ concentration is lowered by the thiazide, and as discussed above, $\mathrm{K}^{+}$-sparing diuretics require calcium to be most effective. The combination of HCT with the loop diuretic TO, however, provides supraadditive natriuretic effects associated with net $\mathrm{K}^{+}-$and $\mathrm{Mg}^{2+}$-sparing effects. Nevertheless, these promising data of our single-dose trial obtained in healthy volunteers have to be validated in short- and long-term clinical trials.
Acknowledgements The generous support of the trial by HEXAL, Holzkirchen, Germany, is greatly appreciated.

Disclosure The authors have no conflict of interest to disclose.

Open Access This article is distributed under the terms of the Creative Commons Attribution Noncommercial License which permits any noncommercial use, distribution, and reproduction in any medium, provided the original author(s) and source are credited.

\section{References}

1. Leiter L (1970) Combinations of diuretics in the treatment of edema. Am Heart J 80:422-424

2. Gunstone RF, Wing AJ, Shani HGP et al (1971) Clinical experience with metolazone in fifty-two African patients: synergy with furosemide. Postgrad Med J 47:789-793

3. Oleson KH (1971) The natriuretic effect of addition of quinethazone and furosemide in congestive heart failure. Acta Med Scand 190:229-232

4. Olesen KH, Sigurd B (1971) The supra-additive natriuretic effect by addition of quinethazone or bendroflumethiazide during longterm treatment with furosemide and spironolactone: permutation trial tests in patients with congestive heart failure. Acta Med Scand 199:233-240

5. Asscher AW (1974) Treatment of frusemide resistant edema with metolazone. Clin Trials J 4:134-138

6. Sigurd B, Olesen KH, Wennevold A (1975) The supra-additive natriuretic effect of addition of bendroflumethiazide and bumetanide in congestive heart failure. Am Heart J 86:163-170

7. Ram CVS, Reichgott MJ (1977) Treatment of loop diuretic resistant edema by the addition of metolazone. Curr Ther Res 22:686-691

8. Epstein M, Lepp BA, Hoffman DS et al (1977) Potentiation of furosemide by metolazone in refractory edema. Curr Ther Res 21:656-667

9. Furrer J, Hess OM, Kuhlmann U et al (1980) Furosemid und Metolazon: eine hochwirksame Diuretikakombination. Schweiz Med Wschr 110:1825-1829

10. Garin EH, Richard GA (1981) Edema resistant to furosemide and metolazone. Int J Pediatr Nephrol 2:181-184

11. Ghose RR, Gupta SK (1981) Synergistic action of metolazone with loop diuretics. Br Med J 282:1825-1829

12. Wollam G, Tarazi R, Bravo E et al (1982) Diuretic potency of combined hydrochlorothiazide and furosemide therapy in patients with azotemia. Am J Med 72:929-938

13. Oster JR, Epstein M, Smoller S (1983) Combined therapy with thiazide-type and loop diuretic agents for resistant sodium retention. Ann Intern Med 99:405-406

14. Arnold WC (1984) Efficacy of metolazone and furosemide in children with furosemide resistant edema. Pediatrics 74:872-875

15. Marone C, Muggli F, Lahn W et al (1985) Pharmacokinetic and pharmacodynamic interaction between furosemide and metolazone in man. Eur J Clin Invest 15:253-257

16. Garin EH (1987) A comparison of combinations of diuretics in nephrotic edema. Am J Dis Child 141:769-771

17. Channer KS, Richardson M, Crook R et al (1990) Thiazides with loop diuretics for severe congestive heart failure. Lancet 335:922923

18. Oimomi M, Takase S, Saeki S (1990) Combination diuretic therapy for severe refractory nephrotic syndrome. Lancet 336:1004-1005 
19. Knauf H, Mutschler E (1993) Low-dose segmental blockade of the nephron rather than high-dose diuretic monotherapy. In: Puschett J, Greenberg A (eds) Diuretics IV. Chemistry pharmacology and clinical applications. Elsevier, Amsterdam, pp 449-456

20. Channer KS, McLean K, Lawson-Matthew P et al (1994) Combination diuretic treatment in severe heart failure: a randomised controlled trial. Br Heart J 71:146-150

21. Fliser D, Schroter M, Neubeck M et al (1994) Co-administration of thiazides increases the efficacy of loop diuretics even in patients with advanced renal failure. Kidney Int 46:482-488

22. Knauf H, Mutschler E (1995) Diuretic effectiveness of hydrochlorothiazide and furosemide alone and in combination in chronic renal failure. J Cardiovasc Pharmacol 26:394-400

23. Knauf H, Wenk E, Schölmerich J et al (1990) Prediction of diuretic mobilization of cirrhotic ascites by pre-treatment fractional sodium excretion. Klin Wschr 68:545-551

24. Ellison DH (1991) The physiologic basis of diuretic synergism: its role in treating diuretic resistance. Ann Int Med 114:886-894

25. Brater DC (1994) Diuretic resistance: mechanisms and therapeutic strategies. Cardiology 84(suppl 2):57-67

26. Knauf H, Mutschler E (1994) Functional state of the nephron and diuretic dose-response-rationale for low-dose combination therapy. Cardiology 84(suppl 2):18-26

27. Knauf H, Mutschler E (1997) Sequential nephron blockade breaks resistance to diuretics. J Cardiovasc Pharmacol 29(3):367-372

28. Black WD, Shiner PT, Roman J (1978) Severe electrolyte disturbances associated with metolazone and furosemide. South Med J 71:381-385

29. Ellison DH (1997) Intensive diuretic therapy: high doses, combinations, and constant infusions. In: Seldin DW, Giebisch G (eds) Diuretic agents. Academic Press, New York, pp 281-300

30. Velazquez H, Knauf H, Mutschler E (1995) Thiazide diuretics. In: Greger RF, Knauf H, Mutschler E (eds) Diuretics, handbook of experimental pharmacology, vol 117. Springer, Berlin, pp 275-334

31. Spahn H, Knauf H, Mutschler E (1990) Pharmacokinetics of torasemide and its metabolites in healthy controls and in chronic renal failure. Eur J Clin Pharmacol 39:345-348

32. Knauf H, Mutschler E (1990) Saluretic effects of the loop diuretic torasemide in chronic renal failure. Interdependence of electrolyte excretion. Eur J Clin Pharmacol 39:337-343

33. Knauf H, Bailay MA, Hasenfuß G et al (2006) The influence of cardiovascular and antiinflammatory drugs on thiazide-induced hemodynamic and saluretic effects. Eur J Clin Pharmacol 62:885892

34. Ellison DH, Velazquez H, Wright FS (1989) Adaptation of the distal convoluted tubule of the rat: structural and functional effects of dietary salt intake and chronic diuretic infusion. J Clin Invest 83:113-126

35. Hropot M, Fowler N, Karlmark B et al (1985) Tubular actions of diuretics: distal effects on electrolyte transport and acidification. Kidney Int 28:477-489

36. Friedman PA, Herbert SC (1997) Site and mechanism of diuretic action. In: Seldin DW, Giebisch G (eds) Diuretic agents. Academic Press, New York, pp 75-111

37. Okusa MD, Persson AEG, Wright FS (1989) Chlorothiazide effect on feedback-mediated control of glomerular filtration rate. Am J Physiol 257:F137-F144

38. Okusa MD, Velazquez H, Ellison DH et al (1990) Luminal calcium regulates potassium transport by the distal tubule. Am J Physiol 258:F423-F428
39. Knauf H, Liebig R, Schollmeyer P et al (1984) Pharmacodynamics and kinetics of etozolin/ozolinone in hypertensive patients with normal and impaired kidney function. Eur J Clin Pharmacol 26:687-693

40. Ellison DH (1997) Adaptation to diuretic drugs. In: Seldin DW, Giebisch G (eds) Diuretic agents. Academic Press, New York, pp 209-232

41. Kaissling B, Bachmann S, Kriz W (1985) Structural adaptation of the distal convoluted tubule to prolonged furosemide treatment. Am J Physiol 248:F374-F381

42. Garg LC, Narang N (1987) Effects of hydrochlorothiazide on $\mathrm{Na}^{+}-\mathrm{K}^{+}$-ATPase activity along the rat nephron. Kidney Int 31:919-922

43. Loon NR, Wilcox CS, Unwin RJ (1998) Mechanims of impaired natriuretic response to furosemide during prolonged therapy. Kidney Int 36:682-689

44. Malnic G, Shigeaki M, Giebisch G (2000) Regulation of potassium excretion. In: Seldin DW, Giebisch G (eds) The kidney, 3rd edn. Lippincott Williams \& Wilkins, New York, pp 15751613

45. Okusa M, Velazquez H, Wright FS (1991) Effect of $\mathrm{Na}^{+}$channel blockers and lumen $\mathrm{Ca}^{2+}$ on $\mathrm{K}^{+}$secretion by rat renal distal tubule. Am J Physiol 260(29):F459-F465

46. Ghys A, Denef J, De Suray M, Gerin M, Georges A, Delarge J, Willems J (1985) Pharmacological properties of the new potent diuretic torasemide in rats and dogs. Arzneim Forsch 35(II):1520 1526

47. Ushida $T$, Yamanaga $K$, Nishikawa M, Ohtaki $Y$, Kido $H$, Watanabe M (1991) Anti-aldosteronic effect of torasemide. Eur J Pharmacol 205:145-150

48. Goodfriend TL, Ball DL, Oelkers W, Bähr V (1998) Torasemide inhibits aldosterone secretion in vitro. Life Sci 63(3):45-50

49. Buffin-Meyer B, Younes-Ibrahim M, Mernissi G et al (2004) Differential regulation of collecting duct $\mathrm{Na}^{+}-\mathrm{K}^{+}$-ATPase and $\mathrm{K}^{+}$ excretion by furosemide and piretanide: role of bradykinin. J Am Soc Nephrol 15:876-884

50. Knauf H, Mutschler E (1992) Constant $\mathrm{K}^{+} / \mathrm{Na}^{+}$excretion ratio during peak diuresis after piretanide but insignificant $\mathrm{K}^{+}$loss during 24 hours. Eur J Clin Pharmacol 43:239-250

51. Reyes AJ, Leary WP, van der Byl K et al (1988) Renal excretory pharmacodynamics of diuretics in man: comparison between furosemide, hydrochlorothiazide and torasemide. In: Reyes AJ, Leary WP (ed) Progress in pharmacology, vol 6, no 3: clinical pharmacology and therapeutic uses of diuretics. Gustav Fischer, Stuttgart pp 83-151

52. Palmer LG, Kleyman TR (1997) Potassium-retaining diuretics: amiloride. In: Greger RF, Knauf H, Mutschler E (eds) Diuretics, handbook of experimental pharmacology, vol 117. Springer, Heidelberg, pp 363-394

53. Netzer T, Ullrich F, Knauf $H$ et al (1997) Potassium-retaining diuretics: triamterene. In: Greger RF, Knauf H, Mutschler H (eds) Diuretics, handbook of experimental pharmacology, vol 117. Springer, Heidelberg, pp 395-421

54. Knauf H, Mutschler E (1984) Pharmakodynamik und -kinetik von Triamteren. In: Mutschler E, Knauf H (eds) 30 Jahre Triamteren. Wissenschafts-Verlag, Köln, pp 31-39

55. Möhrke W, Knauf H, Mutschler E (1997) Pharmacokinetics and pharmacodynamics of triamterene and hydrochlorothiazide and their combination in healthy volunteers. Int J Clin Pharmacol Ther 35(10):447-452 